\title{
KEPATUHAN KONSUMSI TABLET TAMBAH DARAH PADA REMAJA PUTRI
}

\author{
Anita Widiastuti, Rusmini Rusmini \\ Poltekkes Kemenkes Semarang \\ Email : anitawidiastuti123@gmail.com
}

\begin{abstract}
The healthy generation is passed down from the previous healthy generation. For that we need good preparation so that when a pregnant woman is in optimal healthy condition. Healthy conditions will give birth to a healthy generation. Long before becoming pregnant, young women must be prepared to have good health habits. The purpose of this study was to determine compliance with the consumption of added blood tablets in adolescent girls between urban and regional areas. This type of research is descriptive which illustrates adherence of young women in consuming blood-added tablets. The population / research subjects in this study were young women who were targeted by the Fe supplementation delivery program. Schoolgirls have received an added blood packet. In its development there are students who are obedient and there are students who are less obedient in consuming Fe supplementation. For schools in the regions, the consumption of blood added tablets $100 \%$ of respondents spend the added blood tablets that have been received. While for students who are in urban areas who spend less than $50 \%$ add blood tablets. The conclusion that there are still many cases of anemia in schoolgirls who are taking the program added to the tablet added blood. This can be attributed to the awareness that is still lacking in consuming blood-added tablets. It is recommended for schools to be able to help make students aware of consuming blood added tablets that have been given from the government.
\end{abstract}

Keywords: anemia, adolecencts, Fe supplementation

\section{ABSTRAK}

Generasi yang sehat diturunkan dari generasi sehat sebelumnya. Untuk itu perlu persiapan yang baik supaya ketika wanita hamil kondisinya sehat optimal. Kondisi yang sehat akan melahirkan generasi yang sehat. Jauh sebelum hamil remaja putri harus disiapkan untuk memiliki kebiasaan yang baik di bidang kesehatan. Tujuan penelitian ini adalah untuk mengetahui kepatuhan konsumsi tablet tambah darah pada remaja putri antar wilayah kota dan daerah. Jenis penelitian adalah deskriptif yang menggambarkan kepatuhan remaja putri dalam mengkonsumsi tablet tambah darah. Populasi/subjek penelitian dalam penelitian ini adalah remaja putri yang menjadi sasaran program pemberian tablet FE. Siswi sudah mendapat paket tambah darah. Dalam perkembangannya ada siswi yang patuh dan ada siswi yang kurang patuh dalam mengkonsumsi TTD. Untuk sekolah yang berada di daerah, konsumsi tablet tambah darah 100\% responden menghabiskan tablet tambah darah yang sudah diterima. Sementara untuk siswi yang berada di perkotaan siswi yang yang menghabiskan tablet tambah darah kurang dari $50 \%$. Kesimpulan bahwa masih banyak kasus anemia pada siswi yang sedang mengikuti program konsumsi tablet tambah darah. Hal ini bisa dikaitkan dengan kesadaran yang masih kurang dalam mengkonsumsi tablet tambah darah. Disarankan untuk pihak sekolah agar dapat membantu menyadarkan siswa dalam mengkonsumsi tablet tambah darah yang sudah diberikan dari pemerintah.

Kata Kunci:, anemia, remaja putri, tablet tambah darah 


\section{Pendahuluan}

Kualitas hidup sumber daya manusia dimulai semenjak masih dalam kandungan. Generasi yang sehat diturunkan dari generasi sehat sebelumnya. Untuk itu perlu persiapan yang baik supaya ketika wanita hamil kondisinya sehat optimal. Kondisi yang sehat akan melahirkan generasi yang sehat. Jauh sebelum hamil remaja putri harus disiapkan untuk memiliki kebiasaan yang baik di bidang kesehatan.

Gambaran kejadian anemia secara nasional dapat dilihat berdasarkan data Riset Kesehatan Dasar (Riskesdas, 2013). Karakteristik anemia pada remaja di Indonesia tahun 2013 dikelompokkan berdasarkan umur 5-14 tahun 26,4\%, 1524 tahun 18,4\%, 25-34 tahun 16,9\%, 3544 tahun $18,3 \%$, $45-54$ tahun $20,1 \%$, 5564 tahun 25,0\%, 65-74 tahun 34,5\%. Karakteristik anemia berdasarkan jenis kelamin, laki-laki $18,4 \%$ dan perempuan 23,4\%. Jumlah anemia diseluruh Indonesia sebesar 21,7\% (Riskesdes, 2013). Berdasarkan data tersebut, remaja putri masih perlu perhatian khusus untuk terbebas dari anemia. Karena bila wanita hamil mengalami anemia maka kualitas anaknya menjadi kurang baik.

Kementerian kesehatan melalui dirjen Kesehatan Masyarakat mengeluarkan surat edaran No. HK.03.03/V/0595/2016 tentang pemberian tablet tambah darah pada rematri dan wanita usia subur. Pemerintah melakukan upaya preventif dengan memberikan tablet tambah darah untuk remaja putri dan wanita usia subur khususnya yang sedang hamil. Tablet ini diberikan gratis, sedangkan untuk wanita subur yang tidak dalam kondisi hamil diupayakan untuk konsumsi tablet tambah darah secara mandiri.(Dirjen Kesmas, 2016).

Peneliti melakukan studi pendahuluan di sebuah SMP dengan mengukur kadar HB. Dari 133 rematri yang di ukur kadar HB nya, 67 (59,3\%) rematri pada sekolahan tersebut mengalami anemia.

Penelitian yang dilakukan oleh Yuniarti (2015) memberikan gambaran bahwa dari responden yang ikut dalam penelitian, berdasarkan kepatuhan minum tablet Fe di bedakan menjadi kelompok patuh dan tidak patuh. Pada kelompok yang patuh 79,3 tidak mengalami anemia. Sedangkan pada kelompok yang tidak patuh ada $70 \%$ yang mengalami anemia. Ini menunjukkan bahwa program suplementasi FE dapat menurunkan kejadian anemia pada rematri.

Penelitian tentang kepatuhan konsumsi tablet tambah darah memang sudah pernah dilakukan. Namun penelitian untuk mengamati kepatuhan di lingkungan kota dengan lingkungan daerah belum pernah dilakukan. Penelitian ini bertujuan untuk mengetahui gambaran kepatuhan konsumsi tablet tambah darah pada remaja putri di lingkungan perkotaan dengan yang di lingkungan daerah.

\section{Metode Penelitian}

Jenis penelitian adalah deskriptif yang menggambarkan kepatuhan remaja putri dalam mengkonsumsi tablet tambah darah. Populasi/subjek penelitian dalam penelitian ini adalah remaja putri yang menjadi sasaran program pemberian tablet FE. Peneliti mengambil subjek siswi SLTP yang berlokasi di wilayah kota administrative dan di wilayah daerah jauh dari pusat perkotaan.

Sekolah yang di ambil adalah satu sekolah negeri mewakili daerah perkotaan, satu sekolah negeri mewakili daerah bukan kota dan satu sekolah swasta. Peneliti mengambil sampel untuk memberikan gambaran pelaksanaan pemberian TTD masing masing 10 siswi setiap tingkatan kelas. Total survey dilakukan pada 90 siswi dari tiga SLTP.

Pengumpulan data primer dalam penelitian ini dilakukan dengan membagikan kuesioner melalui guruUKS. Data diolah, ditabulasikan dan ditampilkan menggunakan table dan dijelaskan secara deskriptif.

\section{Hasil dan Pembahasan}

Tablet tambah darah adalah suplemen yang mengandung zat besi. Zat besi adalah mineral yang dibutuhkan untuk membentuk sel darah merah (Hemoglobin) (Kemenkes, 2014). Strategi operasional penanggulangan anemia gizi dilakukan melalui pendekatan multi sektoral untuk mencapai kepada sasaran yang diinginkan, seperti pada rematri, 
calon pengantin, ibu hamil/nifas dan pekerja wanita.

Program penanggulangan anemia gizi pada WUS dan rematri ditujukan untuk mempersiapkan kondisi fisik wanita sehingga tidak menurunkan prestasi belajar dan olah raga, kemampuan fisik meningkat, produktifitas kerja meningkat serta mempersiapkan menjadi ibu yang sehat. Pelaksanaan Program Penanggulangan Anemia Gizi berlandaskan pada kemitraan dan pendekatan keluarga, yang berarti penanggulangan anemia gizi harus merupakan upaya dari berbagai sektor terkait dan swasta serta kelompok masyarakat dengan pendekatan pemberdayaan keluarga. Pelaksanaannya dilakukan dalam bentuk kerjasama saling menguntungkan terbuka dan setara guna meningkatkan status kesehatan Rematri melalui kemitraan, mobilisasi potensi dan pemberdayaan keluarga (Kemenkes,2016).

$$
\text { Strategi }
$$
rematri dijabarkan dalam 2 kegiatan pokok (Kemenkes, 2016). Komunikasi, Informasi dan Edukasi (KIE) Kegiatan KIE seperti penyuluhan, konseling, promosi, kampanye dan lainnya tentang anemia dan TTD merupakan kegiatan yang sangat penting dalam rangka meningkatkan pengetahuan, sikap dan perilaku keluarga tentang kesehatan dan gizi khusunya bagi rematri. Promosi juga dilakukan untuk meningkaktan konsumsi keluarga dalam konsumsi sumber-sumber zat besi dari hewan, sayuran dan buahbuahan yang banyak mengandung vitamin $\mathrm{C}$ untuk meningkatkan daya serap besi terurama yang dari sumber nabati. Suplementasi Tablet Tambah Darah (TTD) Tablet tambah darah (TTD) adalah suplemen zat gizi yang mengandung 60 $\mathrm{mg}$ besi elemental dan $0,5 \mathrm{mg}$ asam folat (sesuai rekomendasi WHO). TTD bila diminum secara teratur dan sesuai aturan dapat mencegah dan menanggulangi anemia gizi. Bagi rematri dianjurkan minum TTD secara rutin dengan dosis 1 tablet setiap minggu dan 1 tablet setiap hari pada masa haid.

Pemberian TTD dengan komposisi terdiri dari $60 \mathrm{mg}$ zat besi elemental (dalam bentuk sediaan Ferro furamat atau Ferro Glukonat) dan $0,40 \mathrm{mg}$ asam folat pada rematri usia 12-18 tahun diintitusi pendidikan (SMP dan SMA atau yang sederajat) dan untuk Wanita Usia Subur (WUS) usia 15-49 tahun di institusi tempat kerja.

Pelaksanaan program pemberian TTD bagi rematri dilakukan dengan ketentuan pemberian TTD dengan dosis 1 (satu) tablet per minggu sepanjang tahun. Pemberian TTD dilakukan untuk rematri usia 12-18 tahun. Pemberian TTD pada rematri melalui UKS/M d institusi pendidikan (SMP dan SMA atau yang sederajat) dengan menentukan hari minum TTD bersama setiap minggunya sesuai kesepakatan di wilayah masing masing.

Implementasi pemberian tablet tambah darah (TTD) pada remaja putri dalam penelitian ini adalah suatu kegiatan mengkonsumsi tablet tambah darah yang dilakukan remaja putri. Merupakan program pemerintah melalui pengelola program gizi puskesmas dilakukan di sekolah dengan sasaran remaja putri, melibatkan guru Usaha Kesehatan Sekolah (UKS) atau mata pelajaran lain yang berhubungan. Gambaran survey pelaksanaan pemberian TTD pada remaja putri SLTP ditampilkan pada tabel 1.

Berdasarkan tabel 1 dapat di ketahui bahwa responden sudah terpapat informasi tentang bahaya anemia, cara mengatasi dan pencegahan nya juga gejala anemia. Informasi paling banyak diperoleh dari petugas kesehatan dan tempat pelayanan kesehatan. Selain itu informasi juga diperoleh melalui media. Media yang paling banyak dimanfaatkan oleh informan adalah televisi.

Informasi tentang pentingnya tablet tambah darah untuk remaja putri juga sudah diketahui oleh siswi. Informasi tersebut terkait cara minum tablet tambah darah. Siswi juga terpapar informasi tentang manfaat minum tablet tambah darah bagi remaja. Jumlah tablet tambah darah yang harus dikonsumsi oleh remaja yaitu satu tablet setiap minggu juga sudah diketahui oleh sebagian besar responden. 
Tabel 1. Gambaran survey Persiapan dan Sosialisasi pemberian TTD pada Siswi SLTP

\begin{tabular}{|c|c|c|c|c|}
\hline NO & Pertanyaan & $\begin{array}{l}\text { SMPN } \\
\text { Daerah }\end{array}$ & SMPN Kota & SMP Swasta \\
\hline \multirow[t]{3}{*}{1.} & \multicolumn{4}{|c|}{ Pernah mendapatkan informasi tentang anemia/kurang darah } \\
\hline & YA & 30 & 30 & 30 \\
\hline & TIDAK & 0 & 0 & 0 \\
\hline \multirow[t]{5}{*}{2} & \multicolumn{4}{|c|}{ Informasi apa saja yang didapatkan (jawaban boleh lebih dari 1) } \\
\hline & Bahaya anemia bagi remaja & 14 & 22 & 6 \\
\hline & $\begin{array}{l}\text { Cara mengatasi anemia/kurang } \\
\text { darah }\end{array}$ & 15 & 26 & 19 \\
\hline & Gejala anemia/kurang darah & 12 & 19 & 20 \\
\hline & Lainnya ........... & 0 & 0 & 0 \\
\hline \multirow[t]{7}{*}{3} & \multicolumn{4}{|c|}{ Dari mana mendapatkan informasi tersebut (jawaban boleh lebih dari 1) } \\
\hline & TV & 12 & 3 & 2 \\
\hline & Radio & 0 & 0 & 1 \\
\hline & Koran/Majalah & 4 & 0 & 0 \\
\hline & Dokter/Perawat/Bidan & 24 & 4 & 23 \\
\hline & Puskesmas/Pustu & 4 & 29 & 17 \\
\hline & Lainnya ............ & 0 & 0 & 1 \\
\hline
\end{tabular}

$4 \quad$ Apakah pernah mendapatkan informasi tentang tablet tambah darah untuk remaja putri

Putri

\begin{tabular}{lrrr} 
YA & 30 & 30 & 30 \\
\hline TIDAK & 0 & 0 & 0
\end{tabular}

$5 \quad$ Informasi apa saja yang didapatkan (jawaban boleh lebih dari 1)

\begin{tabular}{llll}
\hline Cara minum tablet tambah darah & 5 & 23 & 8 \\
\hline
\end{tabular}

manfaat minum tablet tambah

\begin{tabular}{llll} 
darah bagi remaja & 22 & 27 & 26 \\
\hline
\end{tabular}

Remaja putri butuh 1

tablet/minggu

$8 \quad 18$

15

Lainnya ..........

$6 \quad$ Dari mana mendapatkan informasi tersebut (jawaban boleh lebih dari 1)

\begin{tabular}{lrrr}
\hline TV & 12 & 3 & 0 \\
\hline Radio & 0 & 0 & 1 \\
\hline Koran/Majalah & 4 & 0 & 2 \\
\hline Dokter/Perawat/Bidan & 25 & 3 & 22 \\
\hline Puskesmas/Pustu & 5 & 28 & 14 \\
\hline Lainnya ........... & 0 & 0 & 0
\end{tabular}

Tabel 2 menunjukkan data bahwa siswi sudah mendapatkan tablet tambah darah program pencegahan anemia. Secara umum siswi yang menjadi responden sudah pernah minum tablet tambah darah semua.

Dalam perkembangannya ada siswi yang patuh dan ada siswi yang kurang patuh dalam mengkonsumsi TTD. Kepatuhan bervariasi, berdasarkan keterlibatan pihak sekolah. Pada sekolah yang guru UKS terlibat langsung dalam pelaksanaan minum TTD, tercatat seluruh informan mengkonsumsi TTD. Pada sekolah yang sama sekali tidak ada yang dilibatkan dalam konsumsi TTD, sebagian besar siswi tidak minum sisa tablet tambah darah yang di berikan. Sedangkan pada sekolahan yang melibatkan siswi dalam pelaksanaan minum TTD, sebagian besar siswi patuh dalam konsumsi TTD. 
Tabel 2. Gambaran survey Pelaksanaan Kegiatan pemberian TTD pada Siswi

\begin{tabular}{|c|c|c|c|c|}
\hline NO & Pertanyaan & $\begin{array}{l}\text { SMPN } \\
\text { Daerah }\end{array}$ & SMPN Kota & SMP Swasta \\
\hline \multirow[t]{3}{*}{1.} & $\begin{array}{l}\text { Apakah anda pernah minum tablet } \\
\text { tambah darah }\end{array}$ & & & \\
\hline & YA & 30 & 30 & 30 \\
\hline & TIDAK (lanjut no 8) & 0 & 0 & 0 \\
\hline 2 & $\begin{array}{l}\text { Tablet tambah darah yang diminum } \\
\text { setiap minggu }\end{array}$ & $\begin{array}{r}1(30 \\
\text { informan) }\end{array}$ & 1(24informan) & 1 (30 informan) \\
\hline \multirow[t]{4}{*}{3} & Kapan anda minum tablet tambah darar & & & \\
\hline & Kadang kadang & 12 & 26 & 11 \\
\hline & $\begin{array}{l}\text { Rutin setiap hari / minggu / } \\
\text { bulan (coret yang tidak perlu) }\end{array}$ & 18 & 2 & 19 \\
\hline & Tidak pernah & 0 & 2 & 0 \\
\hline \multirow[t]{3}{*}{4} & Dari mana mendapatkan tablet tambah & arah & & \\
\hline & Beli/biaya sendiri & 0 & 2 & 0 \\
\hline & Mendapatkan paket tambah darah & 30 & 30 & 30 \\
\hline \multirow[t]{3}{*}{5} & Jika mendapatkan paket, berapa jumlah & tablet yang $\mathrm{d}$ & terima & \\
\hline & tablet/minggu & 1 & 0 & 1 \\
\hline & tablet/bulan & 0 & 4 & 0 \\
\hline \multirow[t]{3}{*}{6} & Apakah tablet tambah darah yang didap & than selalu c & iminum sampai & habis \\
\hline & YA & 30 & 12 & 19 \\
\hline & TIDAK (lanjut no 8) & 0 & 18 & 11 \\
\hline \multirow[t]{5}{*}{7} & Jika jawaban ya, kenapa alasannya (jav & aban boleh It & bih dari 1) & \\
\hline & $\begin{array}{l}\text { Mengikuti nasehat petugas } \\
\text { kesehatan }\end{array}$ & 17 & 4 & 15 \\
\hline & Supaya menjadi remaja yang sehat & 25 & 10 & 16 \\
\hline & Mengikuti nasihat teman/keluarga & 0 & 2 & 1 \\
\hline & Lainnya ........... & 0 & 0 & 0 \\
\hline \multirow[t]{9}{*}{8} & Kendala dalam minum TTD & & & \\
\hline & Mual & 3 & 1 & 9 \\
\hline & Bosan & 1 & 0 & 0 \\
\hline & Tidak suka baunya & 0 & 2 & 2 \\
\hline & Tidak suka rasanya & 1 & 4 & 1 \\
\hline & Malas & 0 & 8 & 5 \\
\hline & Merasa tidak perlu & 0 & 2 & 0 \\
\hline & Tidak tahu manfaatnya & 0 & 0 & 0 \\
\hline & Lainnya ........... & 0 & 0 & 0 \\
\hline
\end{tabular}

Gambaran tersebut dapat dijelaskan berdasarkan hasil penelitian sebelumnya. Hasilnya menunjukkan bahwa adanya dukungan yang diberikan oleh orangtua dalam mengonsumsi TTD tidak menjamin subjek patuh mengonsumsi TTD. Hal ini dapat terjadi karena orangtua hanya mengingatkan saja tanpa memastikan subjek benarbenar mengonsumsi TTD sehingga tidak ada dorongan dalam diri subjek untuk patuh mengonsumsi TTD sesuai anjuran. Sedangkan mayoritas subjek $(75,4 \%)$ mendapatkan dukungan guru yang baik untuk mengonsumsi TTD. Dukungan guru pun diketahui berbeda nyata antara ketiga kelompok perlakuan $(p<0,05)$. Berbeda dengan dukungan orangtua, terdapat hubungan antara dukungan guru dengan kepatuhan konsumsi TTD $(p=0,000) \quad$ Nuradhiani (2018).

Seluruh siswi telah mendapatkan paket tambah darah secara gratis. Namun meskipun sudah mendapatkan secara gratis tidak semua siswi menghabiskan tablet tambah darahnya. Untuk sekolah yang berada di daerah, 
konsumsi tablet tambah darah 100\% responden menghabiskan tablet tambah darah yang sudah diterima. Sementara untuk siswi yang berada di perkotaan siswi yang yang menghabiskan tablet tambah darah kurang dari 50\%.

Siswi juga mengalami kendala dalam minum TTD, kendala yang dialami antara lain ada rasa mual, tidak suka sengan bau ataupun rasa. Dan kendala yang lain adalah adanya rasa malas serta beberapa merasa tidak perlu. Keadaan ini tidak jauh berbeda dengan hasil penelitian yang pernah dilakukan sebelumnya. Menurut Susanti (2016) pada remaja putri di Kabupaten Tasikmalaya, menyatakan alasan tertinggi suplemen tidak dikonsumsi adalah bosan atau malas.

Tabel 3 memberikan gambaran informan tentang status menstruasi. Mayoritas responden sudah menstruasi, keluhan yang banyak dirasakan pada saat menstruasi antara lain pusing dan lemas. Ada juga yang mengalami mata berkunang-kunang dan pucat meskipun hanya sedikit yang mengalami. Keluhan lain adalah mengalami ketidaknyamanan pada perut pada saat menstruasi. Keluhan keluhan di tabel 3 adalah keluhan keluhan pada orang yang mengalami anemia.

Penelitian yang dilakukan Listi (2016) hubungan menstruasi dengan kejadian anemia diperoleh nilai $\mathrm{OR}=2,349$, artinya remaja putri yang menstruasi mempunyai peluang 2,349 kali untuk terkena anemia dibandingkan dengan remaja putri yang tidak menstruasi. Diperkuat juga dengan hasil analisis hubungan konsumsi tablet tambah darah dengan kejadian anemia. nilai $\mathrm{OR}=2,344$, artinya remaja putri yang tidak mengkonsumsi suplemen zat besi mempunyai peluang 2,047 kali untuk terkena anemia dibandingkan dengan remaja putri yang mengkonsumsi suplemen zat besi. Pada penelitian ini meskipun siswi sudah mendapatkan tablet tambah darah gratis dari program, namun masih banyak siswi yang tidak menghabiskan tablet tambah darah tersebut. Sehingga dari gambaran masih banyak ditemukan keluhan yang terjadi saat menstruasi merupakan gejala anemia.

Tabel 3. Gambaran Menstruasi dan Masalah yang Dialami pada Siswi

\begin{tabular}{|c|c|c|c|c|}
\hline $\mathrm{NO}$ & Pertanyaan & $\begin{array}{l}\text { SMPN } \\
\text { Daerah }\end{array}$ & SMPN Kota & SMP Swasta \\
\hline \multirow[t]{3}{*}{1} & Apakah saudara sudah menstruasi & & & \\
\hline & Sudah & 26 & 26 & 23 \\
\hline & Belum (no 2-5 tidak perlu di jawab) & 4 & 4 & 7 \\
\hline 2 & $\begin{array}{l}\text { Kapan mulai menstruasi (Usia dalam } \\
\text { tahun) }\end{array}$ & 11,82 & 11,59 & 12,09 \\
\hline \multirow[t]{5}{*}{3} & Apakah siklus menstruasi saudara tera & & & \\
\hline & Setiap bulan & 25 & 24 & 18 \\
\hline & 2 bulan sekali & 1 & 0 & 0 \\
\hline & 3 bulan sekali & 0 & 1 & 2 \\
\hline & Tidak teratur & 0 & 1 & 3 \\
\hline 4 & $\begin{array}{l}\text { Berapa hari anda biasanya mengalami } \\
\text { menstruasi? }\end{array}$ & 6,42 & 6,22 & 6,67 \\
\hline \multirow[t]{6}{*}{5} & Apakah pada saat menstruasi mengala & .... (jawabar & oleh lebih dar & \\
\hline & Pusing & 6 & 7 & 11 \\
\hline & Lemas & 10 & 12 & 19 \\
\hline & Pucat & 1 & 1 & 0 \\
\hline & Berkunang kunang & 1 & 4 & 2 \\
\hline & Lainnya & Desminore & Desminore & Desminore \\
\hline
\end{tabular}




\section{Simpulan dan Saran}

Kesimpulan bahwa masih banyak kasus anemia pada siswi yang sedang mengikuti program konsumsi tablet tambah darah. Hal ini bisa dikaitkan dengan kesadaran yang masih kurang dalam mengkonsumsi tablet tambah darah. Disarankan untuk pihak sekolah agar dapat membantu menyadarkan siswa dalam mengkonsumsi tablet tambah darah yang sudah diberikan dari pemerintah.

\section{Ucapan Terima Kasih}

Terimakasih banyak kami ucapkan untuk kesempatannya bisa mendapatkan dana Risbinakes DIPA Poltekkes Kemenkes Semarang, sehingga penelitian ini dapat terselesaikan. Ucapan terimakasih disampaikan kepada semua pihak yang ikut berpartisipasi dalam penelitian ini.

\section{Daftar Pustaka}

Almatsier, S. (2009). Prinsip Dasar Ilmu Gizi. Jakarta : Penerbit PT Gramedia Pustaka Utama.

Anggreini, T. V., Husaini, H., Setyaningrum, R., Fakhriadi, R., \& Rosadi, D. (2018). Evaluasi Program Pencegahan Dan Penanggulangan Anemia Remaja Puteri Di SMPN 4 wilayah Kerja Dinas Kesehatan Kota Banjarbaru. Berkala Kesehatan Masyarakat Indonesia, 1(1).

Balitbang Kemenkes RI. 2013. Riset Kesehatan Dasar; RISKESDAS. Jakarta: Balitbang Kemenkes RI

Direktorat Gizi masyarakat (2016). Pedoman pencegahan dan penanggulangan anemia pada remaja putri dan wus.
Dirjen Kesmas. Kementerian Kesehatan Republik Indonesia.

Kemenkes, (2014). Permenkes No 88 Tahun 2014 tentang Standar Tablet Tambah Darah Bagi Wanita Usia Subur dan Ibu Hamil,

http://sinforeg.litbang.depkes.go.id/upl oad/regulasi/PMK No. $88 \mathrm{ttg}$ Tablet Tambah Darah .pdf

Kemenkes RI Dirjen Kesmas, (2016) Surat Edaran Kemenkes No HK.03.03/V/0595/2016 tentang Pemberian Tablet Tambah Darah pada Remaja Putri , http://dinkes.sumutprov.go.id/editor/ga mbar/file/SE\%20TTD\%20Rematri.pdf

Listiana, A. (2016). Analisis faktor-faktor yang berhubungan dengan kejadian anemia gizi besi pada remaja putri di SMKN 1 Terbanggi Besar Lampung Tengah. Jurnal Kesehatan, 7(3), 455-469.

Nuradhiani, A., Briawan, D., \& Dwiriani, C. M. (2018). Dukungan guru meningkatkan kepatuhan konsumsi tablet tambah darah pada remaja putri di Kota Bogor. Jurnal Gizi dan Pangan, 12(3), 153-160.

Susanti Y, Briawan D, Martianto D. 2016. Suplementasi besi mingguan meningkatkan hemoglobin sama efektif dengan kombinasi mingguan dan harian pada remaja putri. J Gizi Pangan 13(1):27-34.

Yuniarti, Y., Rusmilawaty, R., \& Tunggal, T. (2015). Hubungan Antara Kepatuhan Minum Tablet Fe Dengan Kejadian Anemia Pada Remaja Putri Di Ma Darul Imad Kecamatan Tatah Makmur Kabupaten Banjar. Jurnal Publikasi Kesehatan Masyarakat Indonesia, 2(1). 